\title{
Exploring Stakeholder Perceptions of Quality Early Childhood Education in Private Day Care Centers in Ghana: A Qualitative Approach
}

\author{
Belinda Lebene Ami Bamezor, Theophilus Quaicoe, \\ John Boulard Forkuor $(\mathbb{D}$, and Francess Dufie Azumah \\ Department of Sociology and Social Work, Faculty of Social Sciences, \\ Kwame Nkrumah University of Science and Technology (KNUST), Kumasi, Ghana \\ Correspondence should be addressed to John Boulard Forkuor; kforkuor@yahoo.com
}

Received 9 October 2020; Accepted 21 May 2021; Published 1 June 2021

Academic Editor: Enrique Palou

Copyright (C) 2021 Belinda Lebene Ami Bamezor et al. This is an open access article distributed under the Creative Commons Attribution License, which permits unrestricted use, distribution, and reproduction in any medium, provided the original work is properly cited.

\begin{abstract}
In Ghana, despite increasing enrolment, majority of children do not have access to quality early childhood education. The lack of a context-specific and culturally relevant definition of quality in early childhood education is one of the challenges stakeholders face in promoting quality standards in Ghana. In this paper, we use data collected through qualitative semistructured interviews to explore stakeholder definition of quality in early childhood education, the implications of quality, and the key characteristics emphasized in recruiting teachers into quality early childhood education. For the participants, quality early childhood education embodies three key components: safety, nutrition, and teaching. Cognitive development, social skills, and leadership abilities were emphasized as some of the benefits of quality early childhood education for children. Regarding the recruitment of teachers, participants emphasized tertiary education rather than attitudinal and behavioral qualities as relevant for teachers in early childhood education. In view of the emphasis placed on nutrition in defining quality, we recommend that advocacy groups must ensure that the government's school feeding program extends to day care centers. This will go a long way to ensure that children from poor households are not excluded from the benefits of quality early childhood education.
\end{abstract}

\section{Introduction}

In several countries across the globe, state and educational authorities have developed specific policies and implementation frameworks to promote quality and equitable education for all. While education for all is important, experts agree that early childhood education is important as it lays a solid foundation for future academic progress [1]. In recognition of the importance of Early Childhood Care and Education (ECCE), the United Nations (UN) as part of its global development agenda has made ECCE a necessary part of the development agenda of its member countries. To promote and contribute to this developmental agenda by the UN, the United Nations Educational, Scientific and Cultural Organisation (UNESCO) has made it a part of its work to ensure that all boys and girls across the globe have access to not just education but also quality ECCE [2]. UNESCO argues that providing early childhood education presents children with the opportunity to acquire knowledge and develop skills that will have lifelong applicability [2]. The knowledge and skills go beyond educational to include emotional and social development. In other words, ECCE encompasses processes and procedures that provide children with academic, social, and emotional skills as well as the required health and nutrition to stimulate both biological and intellectual development. Some of the existing researches on child development indicate that, by the age of four, a child would have developed a significant amount of their developmental and intellectual potential $[3,4]$. Thus, the training and care a child receives in the early years have 
implications for their future wellbeing. In line with this, UNESCO advocates for children between one and three (1-3) years to have access to at least one year of free but compulsory ECCE delivered by trained personnel in this regard.

Different African states are committed to providing quality ECCE to children across the continent. Some countries have witnessed significant progress in this regard. Nonetheless, there remain a significant number of children across Africa who do not have access to quality ECCE. This is especially so for children from poor households in Africa, most of who are unable to fulfil their full academic potential because of a lack of, or in some cases, poor ECCE [5]. The effects of this lack of, or poor, ECCE on children include poor proficiency and articulation skills [6]. In Ghana, different policies and programs exist to promote quality ECCE. These include, among others, strengthening the capacities of teacher training institutes as well as removing barriers to enrolment for children from poor socioeconomic backgrounds [7]. Ghana's constitution, the Children's Act of 1998, and the Ghana Early Childhood Policy are all legal instruments aimed at promoting the right of children and including access to early childhood education [8]. In Ghana, basic education has been extended since 2004; it begins from the age of three rather than the previous age of six [9]. Ideally, each basic school is expected to make provisions for early childhood care and education through the day care and kindergarten system. The Ministry of Gender and Social Protection through the Department of Social Welfare is in charge of registering day care centers and ensuring that the required standards, quality, and ethical care are provided in each school [9]. Despite economic improvements and improvement in school enrolment over the past few years, poverty and illiteracy rates remain high in Ghana [10]. Majority of day care centers in Ghana are privately owned and operated, despite the government's clear commitment to early childhood care and education [10]. Research suggests that, despite increasing enrolment, the majority of children in ECCE in Ghana do not, or fail to, adequately meet expected developmental benefits from ECCE [10]. Other studies have suggested that teachers in ECCE are limited in their ability to adapt educational ideologies to the specific needs of Ghanaian children in ECCE [11]. Generally, the quality of ECCE has been identified to be low across the country. The lack of measuring instruments and a mode of assessment that is culturally sensitive and specific to subSaharan and African contexts is a major challenge in determining and promoting quality standards in sub-Saharan African countries including Ghana [10].

Achieving quality and competent early childhood education in Ghana, however, depends not only on the development of government policies and strategic programs. Largely, quality early education also depends on the active involvement of stakeholders (including children and parents), the provision of a conducive environment for learning, and the availability of trained and motivated teachers with the relevant educational, attitudinal, and behavioral orientation [12]. While there have been several studies on early childhood education in Ghana $[8,11,13]$, very few have focused on the perception of stakeholders regarding what constitutes quality early childhood education and its implication for the future development of children and society in general. For instance, McCoy and Wolf [10] focused on classroom quality and its impact on child development. On their part, Morrison [14] and Osei-Poku and GyekyeAmpofo [13] focused on curriculum development, teaching methods, and quality of teacher training for early childhood education. Even though these studies provide relevant knowledge for the continuous development of ECCE in Ghana, the lack of knowledge on what constitutes quality from the point of view of stakeholders is problematic. Katz [15] argues that different stakeholders perceive quality ECCE differently. This differing perception has implications for the way in which each stakeholder acts in promoting ECCE. Consequently, it is important that we explore the perception of stakeholders regarding what quality is in ECCE within the Ghanaian context. This knowledge is important because, even with the existence of policies, the perception and interpretation of stakeholders regarding what early childhood education is and its importance will have implications on the way they approach their work. Similar to the above, very little is known about the recruitment processes for teachers by private school head teachers, the quality (intellectual, attitudinal, and behavioral) that they look out for in employing teachers, and the processes of evaluating the performance of teachers. This is also an important aspect of enhancing quality early childhood education, since teachers are important stakeholders and their knowledge, skills, and attitudes have lasting implications on the pupils under their care $[16,17]$.

This paper presents qualitative data on the perception of stakeholders about what "quality" means in early childhood education. The paper further analyses the understanding of stakeholders on the importance of quality ECE for child development. Finally, the paper examines approaches of recruitment of teachers in early childhood education in selected private schools in Ghana.

1.1. Brief Overview of the Literature. In this section, we present a brief overview of the literature on early childhood education. We first examine what quality means in early childhood education and how different authors explore this concept. We further explore teachers as important stakeholders in promoting quality and an overview of the important characteristics that teachers in early childhood education must possess to be effective in their work. Finally, we explore the importance of early childhood education for the cognitive, behavioral, and the general wellbeing of children as they grow.

\subsubsection{Defining Quality in Early Childhood Education.} Quality is one of the most widely debated concepts in ECE research. In assessing and examining the concept of quality in ECE, Ball [18] explains that quality in ECE is a complex concept and that finding a single and/or universal definition may be difficult. Brinkman et al. [12] in exploring the complexity of the concept of quality explain that quality 
early childhood education may be contingent on several variables. The authors explain that any definition of quality must include the characteristics of the classroom and the study environment, the attitudinal and behavioral characteristics of teachers, structural characteristics, and the characteristics of children and their families. Allen and Walley [19] further stress the difficulties associated with defining what exactly quality means within the context of early childhood education. For Waller [20], quality is and must be defined in relation to specific contexts, paying attention to differing values and beliefs regarding children and childhood. Similar to Waller's argument, Moss et al. [21] recognize contexts, values, plurality, and subjectivity as very significant and inclusive factors in determining quality. They consider quality to be value-driven and argue that what is deemed high quality will be influenced by the values and priorities of those who decided what the outcomes and the structures will be [21]. This context-specific and culturally relevant explanation of quality contradicts the restrictive view of quality. Some authors argue that quality in ECE means that guiding laws and policies are developed based on a shared understanding of quality and shared meanings that often originate from the values of Western cultures and contexts [22]. Taken as a whole, the emphasis on different variables in defining quality [12] and the emphasis on contextual and culturally relevant definitions [20] imply that quality in early childhood education may not be obvious and easily assessed. The explanation provided by Katz [15] perhaps provides researchers with more specific guidelines on defining quality in early childhood education. Katz [15] maintains that the quality of early childhood education can be assessed from a variety of perspectives: quality as defined and perceived by the broader society as observers, quality as perceived by children as active participants in their own education, quality as perceived by parents of children as important stakeholders, and quality as perceived by teachers and other actors in education. These perspectives may be complementary or contradictory; nonetheless, as the authors argue, considering the perspectives of different actors in defining quality will help in developing a holistic understanding of quality that addresses the needs of important stakeholders [15].

Even though most scholars subscribe to the relative ideology of quality (cultural values, different interests of stakeholders, and the constructors of childhood shape emphasizing that quality), there is still a debate for conceptualizing common and/or universal parameters of quality [23]. Although there are several instruments for measuring quality in ECE provision, the Classroom Assessment and Scoring System (CLASS) focuses on how teachers and pupils interact within classroom settings and the quality of such interactions [24]. An extensive study by Fourie and Kgalenga [17] focused on best practices for improving the experiential quality of children in ECE. Their research was limited to how communities and practitioners in South Africa worked cooperatively to shape the quality of ECE provision. They assert that since teachers are responsible for preparing children intellectually, socially, and emotionally for future development, any definition of quality ECE must necessarily include teacher characteristics as an important determinant of quality.

While the above literature has explored what quality means and how it may be assessed, most of the literature has been collected from contexts outside Ghana or Africa. While we appreciate the applicability of some of these arguments, we also emphasize that understanding what quality means within the specific Ghanaian context is important and will help to improve the existing approaches to ECE. Thus, in this paper, we explore the perception of stakeholders regarding quality ECE within selected private day care centers in Ghana. Such context-specific understanding of different perceptions of quality will help social welfare officers in general and social workers specifically to make meaningful contributions towards improving the quality of ECE in Ghana.

\subsubsection{Teachers as Important Stakeholders in Promoting} Quality in Early Childhood Education. Motlanthe [25] argues that teachers who have received the required training and are personally interested in childcare are essential in the delivery of quality early childhood education. Fourie and Kgalenga [17] further assert that teachers (caregivers) are responsible for preparing young children for further academic and social development. Consequently, any attempts at improving the quality of ECE must include teachers as active stakeholders considering the role teachers play in moulding children to become contributing members of the global community [16]. While the importance of a teacher in delivering quality ECE is not in doubt, it must be emphasized that, for teachers in ECE to be effective in this regard, they must possess both intellectual and behavioral characteristics that will enhance the quality of their interaction with children. Bean-Mellinger [26] argues that higher education in early childhood education in itself does not make a person a good teacher for children. Colker [27] emphasizes that, to be effective, a teacher in early childhood education must possess the relevant academic training and skills together with personal attributes that have been identified as relevant for working with children. Thus, in addition to the knowledge and skills acquired through a higher education degree, Bean-Mellinger [26] emphasizes that teachers in early childhood education require certain behavioral qualities in order to motivate and help their wards develop as expected. While a lot of researches have been conducted on the required knowledge and skills for teachers in general and especially teachers in higher education, very little research has been conducted on the key personal characteristics needed for teachers in early childhood education [27]. Without underestimating the value of research into required knowledge and skills, we emphasize here that behavioral qualities have significant implications for the performance of teachers in early childhood education. These behavioral qualities stem from years of socialization and are often resistant to change. This explains their implication and significance for teacher effectiveness in early childhood education. Some of these behavioral qualities include 
enthusiasm/passion for children, patience, humour, creativity, and flexibility [26, 27].

While some researches have been conducted on these qualities, very little research has been done on the behavioral qualities of teachers in ECE in Ghana. In addition, the existence of research into the intellectual and behavioral qualities of teachers has implications for teacher recruitment or employment. The implication is that both state and private actors will consider these intellectual and behavioral characteristics in employing teachers into ECE. Within the Ghanaian context, very little is known about how head teachers in private schools recruit and the qualities they look out for in selecting teachers into ECE. It remains unclear whether the qualities they look out for are consistent with or contradictory to some of the qualities identified in the literature. This paper contributes to this gap in knowledge by exploring the characteristics that heads of selected private day care centers look for in recruiting teachers into ECE.

\subsubsection{Quality ECE and Intellectual, Social, and Emotional} Development. Several researchers $[3,4]$ indicate that quality ECE improves academic skills of children beyond basic education. Cortázar's [28] research in Chile concluded that even though socioeconomic status is an important determining variable, generally, both boys and girls receive significant academic benefit from quality early childhood education. In further exploring the relationship between socioeconomic status and early childhood education, Reynolds et al. [29] conclude that children from poor socioeconomic background who have access to quality ECE demonstrate positive academic performance in their secondary education. Thus, despite the socioeconomic status of a child, quality early childhood education has positive implications, enhancing school readiness of children and preparing them intellectually for success in higher education [13]. Research on early childhood education in the United States also indicates that ECE fosters strong academic achievement, at least through elementary school [30]. UNESCO and UNICEF [31] explain that the first three to eight years of a child's life are crucial to the child's brain development. As a result, quality early childhood education is likely to benefit the future academic wellbeing of children. Barnard [32] goes beyond the intellectual benefit of early childhood education and emphasizes other benefits such as social and emotional benefits.

Child socioemotional competence is a broad term for a diverse array of social and emotional skills and behaviors such as the regulation of emotional experience and expressiveness as well as the sustenance of engagement with peers [33]. The significance of children's socioemotional competence for general life changes and the role early childhood education plays is acknowledged by researchers and academics from different disciplines [34]. Broekhuizen [35] asserts that quality ECE is the strongest predictor of a child's social and behavioral skills. Some psychologists argue that being part of a group within educational environments enhances the child's social development and communication skills [36]. When children experience quality early childhood education, they build self-confidence, develop an interest in pursuing higher education, and are able to develop healthy relationships with friends and classmates [37]. Children at early childhood education stage discover themselves while playing freely, and this contributes greatly to the development of their linguistic capacities, cognitive skills, and other motor skills such as coordination, endurance, and balance [38].

\section{Research Methods}

This paper reports data from a broader study which relied on both qualitative observations and interviews. The data reported in this paper is from the semistructured interviews and focuses on one of the main themes of the broader study (the meaning of quality ECE and its perceived implications for child development). Authors collected data from three privately owned day care centers in the Kumasi Metropolis of Ghana. Authors purposively selected 30 participants as part of this study. The number of participants was determined by the resources available to researchers (time and financial) as well as the availability and willingness of participants. The participants included parents, caregivers, and proprietors or head teachers. As indicated in the literature, these are important stakeholders and their conception of what quality means is important.

This study used semistructured qualitative interviews to collect data from participants, focusing on their perception about what quality means in early childhood education, the implication of quality early childhood education for child development, and the qualities emphasized in selecting teachers to teach in early childhood educational centers. Authors received institutional consent from all the selected institutions for data collection. All participants gave individual verbal consent to participate in the study. Authors assured participants that their information will be used for the purpose indicated and that their identity will be kept anonymous in all publications. We have upheld this ethical responsibility by not indicating the names of the institutions involved and using pseudonyms to represent the participants involved in this study. All participants gave their consent for the interviews to be audio recorded. The first and second authors conducted the interviews in the English Language and each interview lasted for approximately 35 minutes.

All the interviews were transcribed verbatim. The main research questions that guided the study were used to reorganize the transcript. Thus, in addition to the original transcript containing the full transcribed interviews for all participants, the authors generated a second transcript using the main research questions as a guide. In this second transcript, the specific responses of participants to different questions of the study were grouped. For instance, under the first research question, the responses of each participant to that question were copied and pasted. This organized transcript served as the main document on which the codes and themes were developed. The third author, together with the first and second authors, read through the responses under each research question and used keywords or phrases 
to represent important ideas. These were the initial codes developed. These codes were developed directly from the data in relation to specific research questions. Codes presenting specific sets of ideas were merged into broader themes. The authors used these themes to present the results under each of the research questions of interest. The fourth author used the themes to develop the first full draft of this manuscript after which all authors contributed to further developing the manuscript and preparing it for submission.

2.1. Overview of Study Participants. Table 1 presents a brief overview of the participants in this study. The participants in this study (parents, caregivers, and proprietors) included 19 females and 11 males. Most of the participants were aged between 27 and 50 years, with only three participants aged 50 years or more. Almost all the participants had at least basic education. Interestingly, most of the parents had higher educational degrees compared to the teachers and caregivers, most of whom had either secondary education certificates or diplomas and HNDs.

2.2. Findings. In this section, we present the findings to address the key objectives informing this study. We first explore the perception of participants regarding quality ECE. We follow this with an exploration of the perception of participants regarding the effects of quality ECE on child development. We follow this with an exploration of the processes and procedures through which teachers with the required qualities are recruited into ECE. In presenting the results, the identities of participants are replaced with pseudonyms such as "P1" which represents first parent, "CA 1 ," for first caregiver, "PR1," for first proprietor, "CM1," for first community member, and so forth.

\subsubsection{Perception of Participants Regarding Quality Early} Childhood Education. The analysis revealed that, for participants in this study, quality ECE means safe and secure environment for studies, the availability of nutritious food, and the presence of teachers with the appropriate qualities to enhance the learning experience of pupils.

\subsubsection{Safety as an Important Determinant of Quality ECE.} All the participants emphasized the security of the school environment as an aspect of quality early childhood education provision. CM4, one of the community members, summarizes the relevance of security in the following way: "I believe that quality education requires good security and good environment." For the participants, safety and security mean the presence of physical security measures, for instance, the presence of security officers, CCTV cameras, and visitor logbooks as well as the attentiveness of teachers to these security protocols. The following narratives by parents and one school proprietor emphasize the importance of safety and security for participants.

"To me, it is the environment of the school, including the security measures in place and how well the teachers take
TABLE 1: Bio-data of study participants.

\begin{tabular}{|c|c|c|c|c|}
\hline $\mathrm{SN}$ & Participant & Gender & Age & Educational background \\
\hline 1 & P1 & Female & 33 & First degree \\
\hline 2 & $\mathrm{P} 2$ & Male & 37 & First degree \\
\hline 3 & P3 & Female & 38 & First degree \\
\hline 4 & $\mathrm{P} 4$ & Female & 39 & HND \\
\hline 5 & P5 & Male & 40 & $\mathrm{PhD}$ \\
\hline 6 & P6 & Female & 29 & Diploma \\
\hline 7 & P7 & Male & 35 & Master's degree \\
\hline 8 & P8 & Male & 33 & Master's degree \\
\hline 9 & P9 & Female & 30 & Master's degree \\
\hline 10 & $\mathrm{P} 10$ & Male & 59 & Master's degree \\
\hline 11 & CA1 & Female & 27 & Diploma \\
\hline 12 & CA2 & Male & 31 & HND \\
\hline 13 & CA3 & Female & 28 & Diploma \\
\hline 14 & CA4 & Female & 28 & SHS \\
\hline 15 & CA5 & Female & 45 & None \\
\hline 16 & CA6 & Female & 43 & SHS \\
\hline 17 & CA7 & Female & 32 & SHS \\
\hline 18 & CA8 & Male & 28 & First degree \\
\hline 19 & CA9 & Male & 25 & First degree \\
\hline 20 & CA10 & Female & 31 & SHS \\
\hline 21 & PR1 & Female & 43 & Master's \\
\hline 22 & PR2 & Female & 76 & CERT A PROSEC \\
\hline 23 & PR3 & Male & 28 & Undergraduate student \\
\hline 24 & PR4 & Male & 39 & First degree \\
\hline 25 & CM1 & Male & 62 & SSCE \\
\hline 26 & CM2 & Female & 58 & Form 4 \\
\hline 27 & CM3 & Female & 40 & None \\
\hline 28 & CM4 & Female & 35 & SHS \\
\hline 29 & CM5 & Female & 45 & SHS \\
\hline 30 & CM6 & Female & 31 & JHS \\
\hline
\end{tabular}

care of the children. At this center, whenever I am unable to pick up my child and I do not call ahead, they would not let whomever I send to pick my ward up do so unless I have been contacted, and that is very good to me" (P5).

"The environment is great and the security is ok. In fact, apart from the security at the gate, within the premises, there are CCTV cameras and the caregivers do not give the child to anyone unless I have authorized it to be so" (P6).

"We have security men who ensure that no child gets out of the main gate and there are CCTV cameras around, they have to be fed well, teacher to child ratio is very great and we have great ventilation in the classes to allow great circulation of air" (PR2).

Within the study context, this emphasis on safety may be a reflection of the strong communal and traditional value placed on the protection of children [39]. A reflection of the cultural belief is that one of the qualities of a good parent is an ability to protect children from harm and to keep them safe. In this study, the school (during school hours) assumes the responsibility of a parent and is thus expected to uphold the same cultural values and expectations of parents, including the safety and protection of children. In sum, the security measures and physical structures that day care centers put in place are an important part of the participants' 
conceptualization of quality. Quality here goes beyond taught content to include environmental safety, safety protocols, and teacher attentiveness.

2.2.3. Nutrition as a Determinant of Quality ECE. In addition to environment and safety measures, participants indicated that the nutritional value of the meals provided to the children is an important determinant of quality ECE: "Providing nutritious meals are also requisite for ensuring the health and development of the children as part of enhancing quality education. We provide the children with their lunch which are balanced along with fruits" (CA4). Evidently, balanced and nutritious food is one of the ways by which participants define and ensure quality ECE. The importance placed on this is evident in the following quotation from CA2.

"The cooks get adequate training from KMA every six months and the food provided for the children are highly nutritious. They eat thrice a day. Sometimes they bring their meals from the house. We check the meal to ensure it is very nutritious" (CA2).

From the above, where the school provide meals, they ensure that their caterers have adequate training from the metropolitan directorate. On the other hand, where pupils bring their own food, teachers take it upon themselves to ensure that the foods are nutritious. To these participants, it is necessary to ensure that every meal provided for the children is well balanced and given on time. All the participants believe that nutritional provision is an important factor in the provision of quality early childhood education as it deals with ensuring the health and growth of the children. This emphasis on nutrition could also be explained as relevant especially within the study context. For some children from deprived communities and homes, the food provided in schools may be the only nutritious food available to them. The availability of nutritious food in schools therefore has positive implications for school attendance $[40,41]$. It allows children from poorer homes to attend and remain in school and enhance their attentiveness and subsequently their performance. Hence, as participants in this study emphasize, for quality to occur, children need to be able to stay in school and remain attentive, something that is achieved through the provision of nutritious food $[40,41]$.

2.2.4. Teaching as an Important Part of Quality ECE. Participants emphasized teaching methods and approaches as an important part of quality ECE, especially for enhancing the cognitive skill of pupils. CA1 explains how a combination of indoor and outdoor activities enhances the quality of ECE and promotes the development of the child.

"In teaching, you want to help the child to acquire knowledge, develop his or her cognitive, assertive skills and domain, but outdoor activities deal with how they can be sociable with their peers and how they can mentor others. At the playground, many things go on, it helps to develop their gross and fine motor skills; the use of the play cars, bicycles, tricycles and football help develop these skills" (CA1).

"We teach rhymes and do the actions to let the children know how to do it. Some children are difficult and others are soft-hearted. As such in assessing them as they play, we try to observe those who seem more active on the playground in comparison to being in the classroom and vice versa" (CA4).

"We let them participate in scribbling, painting, and poem recitals as these help them in developing their fine motor skills" (CA10). Most of the participants also referred to the outdoor activities as a way of creating playful scenery for the children and avoid the too structured form of education since they are children.

In conclusion, all the day care centers engage the children in both teaching and outdoor activities as a way of ensuring good childcare and improving their development.

2.2.5. Implications of Quality ECE on Child Development. Another objective of this study was to explore the perception of participants regarding the implication of quality ECE for the future wellbeing of the child. Most participants indicated that ECE provides a good foundation (in terms of the development of social and cognitive skills) for children as they grow, making them prepared for higher education and welladjusted social actors.

Most participants emphasized the role ECE plays in providing a good foundation for the future academic development of children: "one positive aspect of ECE is that it serves as a good foundation, as long as they have quality teachers" (CA1). For the participants, gaining early speech skills and engaging in role-playing and confidence-building activities all give the children relevant skills for future academic excellence: "It prepares them for the higher level that is the foundation for their education" (CA3). For CA10, not only does quality ECE provide a good foundation for children but also it allows teachers at higher educational levels to do their job: "It serves as the foundation of their educational level. It makes work easier for continuing teachers hence serving as a good foundation for the children" (CA10). CM3 provides a similar argument when she states the following: "It broadens their mind so much that when they get to Kindergarten it is easier for them to adjust well unlike those who do not have the day nursery education." It is evident that, for these stakeholders, not only is quality ECE relevant for the children, but also it has an important implication on a country's higher educational system. In addition to its implication for the educational system, CM6 suggested broader implications of ECE for society. CM6 explains that quality ECE has implication for social functioning, as children who have quality ECE are perceived to have better social skills and follow social norms: "It serves as a good foundation and they react and comport themselves when in public." 
In further exploring the exact nature of this good foundation, participants were asked to indicate some of the specific skills that children develop through quality ECE. With reference to these, participants' responses focused on the development of four key skills: cognitive, emotional, social, and physical skills. For one participant, their socialization skills are always developed: "They develop socially by interacting with their peers through learning and playing" (CA2). For another participant, ECE enhances the leadership, cognitive, and social skills of children.

"From the start, it helps broaden their minds because they become clever than they would if they were at home. When they come back from school, they behave like their teachers and pretend to do what they do in the class. Coming to this day care center, has helped my kids socialize well with others and it has been a very good foundation in enhancing their English language” (P4).

Another participant's assessment of the effect of early childhood education was that it allowed the child to exhibit independence and take initiative; this participant stated the following:

"My ward now speaks better, has become independent and socializes well. Her manners too have improved she says sorry when she does wrong, and says thank you to praise and gifts" (P5). To another participant, their intellectual and speaking skills are developed: "The children are able to learn how to speak, write, sing and even socialize with their peers quite well" (CM5).

In conclusion, the implication of quality ECE is that it lays the proper foundation for the children in terms of higher education. It makes them well-adjusted social actors and enhances higher education teaching as well. Whether they are social, physical, cognitive, mental, emotional, or intellectual skills, quality ECE helps in improving them.

\subsubsection{Processes and Procedures in the Recruitment of} Teachers. As indicated in the literature, teachers are important stakeholders in providing quality ECE. Consequently, recruiting the teachers with the relevant attitude, knowledge, and skills and monitoring their performance are crucial in promoting quality ECE. In this section, we present results on the recruitment practices of the selected schools as well as the training and experience of other staff. The strategies that head teachers use to evaluate teachers and maintain quality standards are subsequently presented. For this study, participants emphasized academic qualification and work experience as the most important determinants. The following quotations indicate the importance that participants place on academic qualification and prior work experience.

"Depending on the role they are to play, the educational requirements include a minimum of Basic Education certificate, a first-degree holder with experience in working with children, as well as Postgraduates. It is also dependent on the role the person is applying to, the teaching role requires having a certificate in Basic education, graduates and postgraduates are highly considered. For the other staff such as the cooks, they have to be certified by the Kumasi Metropolitan Assembly before they are employed” (PR1).

"It is an open opportunity to all manner of people who qualify to come in. No discrimination whatsoever, either in background, disability, culture or beliefs. The main criteria are having WASSCE certificate with good grades and fluent in English. But those with a higher educational qualification are the main teachers. Other criteria include being healthy, if you are a person who is always sick you cannot do the work since you are handling children. . .The minimum educational qualification we ask from the caregivers is having Senior High School certificate. For higher positions too, having a diploma or degree in any field such as nursing and teaching is given priority" (PR4).

"The criteria for choosing the applicant depend on having at least a WASSCE certificate, an experience for working with children and at times their age. After they are selected, they undergo a one-year training period at the Department of Social Welfare" (PR2).

While PR1 and PR4 emphasize academic qualification, PR2 goes further to indicate the importance of prior experience with children. In further explaining the relevance of prior work experience of potential ECE teachers, PR3 emphasizes the following.

"Experience is actually one of our main criteria for recruiting our caregivers; hence we look at how they deal with issues involving the children they are assigned to as well as how well they communicate with the parents" (PR3).

Here, PR3 appears to indicate the importance of a relevant attitude, through prior experience with children, as an important determinant for selecting teachers into ECE to enhance quality. In most of the responses though, the main emphasis was on educational/academic qualification with little or no emphasis on relevant attitudinal and behavioral qualities of the teachers.

\section{Discussion}

This study sought to explore the perception of stakeholders regarding the meaning of quality in early childhood education, the implication of quality early childhood education, and the qualities that are looked out for in the recruitment of teachers into quality ECE.

For the participants of this study, quality ECE embodies three key components: safety, nutrition, and teaching. For quality in ECE, children must first learn within an environment that is safe not only from external criminal activities but also from injury and harm from the school infrastructure. In addition to this, children must have access 
to nutritious food within the school environment. Finally, relevant approaches to teaching and relevant content are important determinants of quality ECE. While the existing literature emphasizes that quality ECE is not necessarily universal $[18,20]$, the components of ECE as highlighted by participants in this study are similar to those emphasized by Brinkman et al. [12] and Waller [20]. However, unlike the components of quality ECE as emphasized by Brinkman et al. [12], participants in this study did not emphasize the behavioral characteristics of teachers and children as an important determinant of quality ECE. This may be an important limitation in the conception of quality ECE considering the argument by Fourie and Kgalenga [17]. The authors argue that, without considering the characteristics of teachers, we fail to define what quality ECE is given the important role that teachers play. Nonetheless, the difference in definition and the lack of emphasis on the characteristics of teachers may also be because of the context of the study. The argument made by Waller [20] and Moss and Dahlberg and Pence [21] that any definition of quality ECE is relative and is embedded within the culture and context within which it is defined could explain this difference in definition. To emphasize, participants in this study identified nutritious diet as a determinant of quality ECE without emphasizing the characteristics of teachers and students. According to Waller [20], the definition of quality ECE also depends on the cultural values and beliefs regarding children and childhood within the study context. Though globalization and modernization are changing various aspects of the Ghanaian culture, it is still true that, for most Ghanaians, older persons are wiser, well behaved, and mature and that children are supposed to look up to adults to guide them morally and behaviorally $[42,43]$. The contextual cultural assumption about the maturity and "behavioral correctness" of adulthood may help explain the exemption of the appropriate character of teachers in the definition of quality ECE by this study's participants. In other words, in the study context, teachers are expected to possess the right attitude and behavior in their role as adult members of society. We argue that the lack of emphasis on the character of teachers may not necessarily mean that this is not an important requirement for quality ECE in Ghana. The emphasis that participants placed on nutrition may also have contextual explanation and value. Nutrition plays an important role in the education of Ghanaian children in basic schools. The Government of Ghana used nutrition as a strategy to increase enrolment at the basic level in a bid to increase the literacy rate. This strategy, seen in the implementation of the School Feeding Programme (SFP) in 2005 [44], has increased the attendance of students at the basic level by lowering the opportunity costs of attending school and providing additional incentives to engage in learning (formal education) [40]. Through nutrition, a child who is interested in learning can be retained in school to gain the intended results of education [45] while improving the attentiveness and absorption (quality learning) of children within basic schools [41]. This school feeding program, however, does not apply to children in day care settings, hence the emphasis placed on nutrition as an important component of quality ECE.

While this study explored quality as perceived by teachers and parents as key stakeholders, children were not included. This exclusion of children in defining quality is an important limitation, especially as this study sets out to explore what quality ECE is within the study context. Katz [15] emphasizes that even though quality can be defined from a variety of perspectives, any definition must include children as active participants in their education. An important question for future research will be how children in ECE in Ghana perceive quality and what children consider as important for them in their educational development.

In order for stakeholders to promote quality ECE, they must appreciate the relevance of quality ECE for the future development of children as well as for society as a whole. In this study, participants indicated three main benefits of promoting quality ECE. Participants explained that quality ECE enhances the cognitive development of children, giving them an advantage in their future academic studies. In addition to cognitive development, participants emphasized improved social skills as well as leadership skills as benefits of quality ECE. These findings are similar to those of Cortázar [28] and Osei-Poku and Gyekye-Ampofo [13]. These authors emphasize that the benefits of quality ECE are evident for children, irrespective of gender and socioeconomic background. Other authors emphasize the socioemotional and behavioral benefit of quality ECE $[32,35]$. The leadership skill that was emphasized by participants is similar to the argument by Steyn et al. [37] that self-confidence and selfmotivation are two of the key benefits of quality ECE. The fact that participants in this study are aware of the benefits of quality ECE for the future social, academic, and emotional development of children may have positive implications on their actions, policies, and practices aimed at promoting quality. Since this research did not explore the relationship between knowledge and practices to make a conclusive statement on this, we suggest that future researchers explore whether knowledge of the benefits of quality ECE actually informs policies and practices within day care centers in Ghana. From the responses of participants in this study, it is clear that the benefits of quality ECE focus mainly on the child and their individual development without emphasizing the implication for societal progress and development.

Teachers play an important role in promoting quality ECE. Consequently, the characteristics of teachers who work in early childhood education are important determinants of quality. From this study's participants, the main characteristics that make a person qualified to teach in early childhood education are their academic qualification, their state of health, and, to some extent, prior work experience. In other words, intellectual competence appears to be more important for participants rather than behavioral competence. While participants mostly emphasized having a degree as an important quality, Bean-Mellinger [26] and Colker [27] argue that having a higher educational degree alone does not make a person qualified for early childhood 
education. The authors emphasize enthusiasm and patience as some of the important behavioral characteristics that teachers in ECE must possess. While we cannot say for sure that these attributes are not important to our participants, what we can say is that the focus of key stakeholders in this study on academic qualifications may indicate a need for further education about the importance of behavioral competence towards enhancing quality ECE. In addition, Ghanaian researchers and social workers must engage with partners in industry to develop ways of assessing these behavioral characteristics and using them in selecting potential or would-be teachers in ECE. We argue that the Department of Social Welfare should incorporate these in their criteria for assessing early childhood educational centers and increase the awareness of the proprietors to inform future recruitment processes.

\section{Conclusion and Recommendations}

This study provides an insight into the perception of selected stakeholders in ECE about what quality means, the implications of quality ECE, and the key characteristics emphasized in recruiting teachers into ECE. Even though the environment, safety, and the quality of teaching were all recognized, the behavioral qualities of teachers in ECE were not emphasized by the participants in this study. Participants emphasized the availability of nutritious food as an important component of quality ECCE. In addition to the limitation in scope, this research failed to explore the perception of children as important and active stakeholders in their education. This is an important theme that future research into quality ECE in Ghana must focus on. Furthermore, we recommend that subsequent researchers incorporate external stakeholders such as the Ministry of Education, Ghana Education Service, Department of Social Welfare, and educational policy analysts in their study. For social welfare officers and practitioners in Ghana, the benefits of ECE, irrespective of socioeconomic background, indicate an urgent need for ECE to be made available to children from poor households. Available evidence confirms that children from poor households experience weak early childhood education system, which leads to their overall poor performance in higher education [6]. Consequently, advocacy groups must ensure that the government's free education, including school feeding, extends to day care centers for children from poor households. This will go a long way to ensure that children from poor households are not excluded from the benefits of quality ECE.

\section{Data Availability}

The underlying data are not available for the public.

\section{Conflicts of Interest}

The authors declare that they have no conflicts of interest.

\section{References}

[1] M. Geo-Jaja and J. Zajda, "Rethinking globalization and the future of education in Africa," in International Handbook on Globalisation, Education and Policy Research, pp. 109-129, Springer, Dordrecht, Netherlands, 2005.

[2] UNESCO, "Early childhood care and education (ECCE)," Education Sector Technical Notes, UNESCO, Paris, France, 2013, https://unesdoc.unesco.org/ark:/48223/pf0000222118.

[3] W. S. Barnett, "Effectiveness of early educational intervention," Science, vol. 333, no. 6045, pp. 975-978, 2011.

[4] D. A. Phillips and A. E. Lowenstein, "Early care, education, and child development," Annual Review of Psychology, vol. 62, pp. 483-500, 2011.

[5] World Bank, Learning to Realise Education's Promise, World Bank, Washington, DC, USA, 2018, https://www.worldbank. org/wdr2018.

[6] N. Altinok, N. y. Angrist, and H. A. Patrinos, "Global data set on education quality (1965-2015)," Policy Research Working Paper (Report No. 8314), Education Global Practice Group of World Bank, Washington, DC, USA, 2018, https://revistas. uam.es/jospoe/article/view/9809.

[7] M. Okai and A. K. Amoah, "How far with Ghana's early childhood care and development? ModernGhana, August 2016, https://www.modernghana.com/news/715064/how-farwith-ghanas-early-childhood-care-and-development.html.

[8] A. Abdulai, "Challenges facing ealry childhood education in Ghana. What do stakeholders say?" Advances in Social Sciences Research, vol. 1, no. 3, pp. 11-34, 2014.

[9] R. Chawla-Duggan, K. Etsey, and V. Datta, "Early childhood care and education in Ghana and Maharashtra," EdQual Policy Brief No. 9, EdQual, University of Bristol, Bristol, UK, 2010, https://www.edqual.org/publications/policy-briefs/ edqualpb9.pdf/at_download/file.pdf.

[10] D. C. McCoy and S. Wolf, "Changes in classroom quality predict Ghanaian preschoolers' gains in academic and socialemotional skills," Developmental Psychology, vol. 54, no. 8, pp. 1582-1599, 2018.

[11] K. Akyeampong, "Teacher educators' practice and vision of good teaching in teacher education reform context in Ghana," Educational Researcher, vol. 46, no. 4, pp. 194-203, 2017.

[12] S. A. Brinkman, A. Hasan, H. Jung, A. Kinnell, N. Nakajima, and M. Pradhan, "The role of preschool quality in promoting child development: evidence from rural Indonesia," European Early Childhood Education Research Journal, vol. 25, no. 4, pp. 483-505, 2017.

[13] P. Osei-Poku and M. Gyekye-Ampofo, "Curiculum delivery in early childhood education: evidence from selected public kindergarten in Ashanti region," British Journal of Education, vol. 5, no. 5, pp. 72-82, 2017.

[14] K. Morrison, "Educational philosophy and the challenge of complexity theory," Educational Philosophy and Theory, vol. 40, no. 1, pp. 19-34, 2008.

[15] L. G. Katz, Multiple Perspectives on the Quality of Early Childhood Programs, Eric Digests, Urbana, IL, USA, 1993, https://files.eric.ed.gov/fulltext/ED355041.pdf.

[16] D. Bell, R. E. Jean-Sigur, and Y. A. Kim, "Going global in early childhood education," Childhood Education, vol. 91, no. 2, pp. 90-100, 2015.

[17] E. Fourie and R. Kgalenga, "The impact of school principals on implementing effective teaching and learning practices," International Journal of Education Management, vol. 32, no. 6, pp. 1056-1069, 2014. 
[18] C. Ball, Start Right: the Importance of Early Learning, Royal Society for the encouragement of Arts, Manufactures, and Commerce, London, UK, 1994, https://files.eric.ed.gov/ fulltext/ED372833.pdf.

[19] S. Allen and M. E. Walley, Supporting Pedagogy and Practice in Early Years Settings, Exeter: Learning Matters, Exeter, UK, 2010.

[20] T. Waller, An Introduction to Early Childhood: A Multidisciplinary Approach, Paul Chapman, London, UK, 2005.

[21] P. Moss, G. Dahlberg, and A. Pence, "Getting beyond the problem with quality," European Early Childhood Education Research Journal, vol. 8, no. 2, pp. 103-115, 2000.

[22] M. Woodhead, "Changing perspectives on early childhood, theory, research and policy," International Journal of Equity and Innovation, vol. 4, no. 2, pp. 1-43, 2006.

[23] A. Monney, The Effectiveness of Quality Improvement Programmes for Early Childhood Education and Childcare, University of London Press, London, UK, 2007.

[24] C. R. Pianta, K. M. LaParo, and B. K. Hamre, Classroom Assessment Scoring System: Manual Pre-K, Paul H. Brookes Publishing Co., Baltimore, MA, USA, 2008.

[25] K. Motlanthe, "Quality of schooling not what it should be. Politicsweb," 2011, https://www.politicsweb.co.za/opinion/ quality-of-schooling-not-what-it-should-be--kgalem.

[26] B. Bean-Mellinger, "Qualities of a good teacher in early childhood development," June 2018, http://work.chron.com/ qualities-good-teacher-early-childhood-development-8694. html.

[27] L. Colker, "Twelve characteristics of early childhood teachers," Journal of National Association for the Education of Young Children, vol. 63, no. 2, pp. 68-73, 2008.

[28] A. Cortázar, "Long-term effects of public early childhood education on academic achievement in Chile," Early Childhood Research Quarterly, vol. 32, pp. 13-22, 2015.

[29] A. J. Reynolds, K. A. Magnuson, and S.-R. Ou, "Preschool-tothird grade programs and practices: a review of research," Children and Youth Services Review, vol. 32, no. 8, pp. 11211131, 2010.

[30] G. Camilli, S. Vargas, S. Ryan, and W. S. Barnett, "Metaanalysis of the effects of early education interventions on cognitive and social development," Teachers College Record, vol. 112, no. 3, pp. 579-620, 2010.

[31] UNESCO and UNICEF, "Asia-pacific end of dacade notes on education for all: early childhood care and education," UNESCO Bangkok, UNICEF EAPRO \& UNICEF ROSA, Bangkok, Thailand, 2012.

[32] W. M. Barnard, Early Intervention Participation, Parent Involvement in Early Schooling and School Successs, University of Wisconsin-Madison, Madison, WI, USA, 2003.

[33] L. Rose-Krasnor and S. Denham, "Social-emotional competence in early childhood," in Social, Emotional, and Personality Development in Context. Handbook of Peer Interactions, Relationships, and Groups, K. H. Rubin, W. M. Bukowski, and B. Laursen, Eds., pp. 162-179, The Guilford Press, New York, NY, USA, 2009.

[34] K. Vander Van, Promoting Positive Development in Early Childhood: Building Blocks for a Successful Start, Springer, New York, NY, USA, 2008.

[35] M. Broekhuizen, "Differential effects of early child care on child's socio-emotional development," Doctoral dissertation, Utrecht University, Utrecht University Dspace Library, Utrecht, Netherlands, 2015, https://dspace.library.uu.nl/ bitstream/handle/1874/306811/broekhuizen.pdf? sequence=1.
[36] M. R. Jalongo, “"What are all these dogs doing at school?": using therapy dogs to promote children's reading practice," Childhood Education, vol. 81, no. 3, pp. 152-158, 2005.

[37] M. G. Steyn, T. Harris, and C. G. Hartell, "Where are foundation phase teachers for our children? Black students perceptions," South African Journal of Higher Education, vol. 25, no. 3, pp. 583-597, 2011.

[38] M. Ouvry, Engaging Muscles and Minds: Outdoor Play and the Early Years Curriculum, National Children's Bureau, London, UK, 2003.

[39] K. Frimpong-Manso, "Child welfare in Ghana: the past, present and future," Journal of Education and Social Research, vol. 4, no. 6, pp. 411-418, 2014.

[40] O. N. Awojobi, "A systematic review of the impact of Ghana's school feeding programme on educational and nutritional outcomes," Agro-Science, vol. 18, no. 2, pp. 42-50, 2019.

[41] I. Tagoe, "The Ghana national school feeding program: peoples' perceptions about the program's impact on school enrolment, attendance and completion," Bowling Green State University, Bowling Green, OH, USA, 2018, https://etd. ohiolink.edu/!etd.send_file?accession=bgsu152168286929824 6\&disposition=attachment.

[42] S. Mahama, V. Tackie-Ofosu, and N. Y. Nyarko, "Conceptions of adulthood: perspectives from Ghana," IFE Psychologia, vol. 26, no. 1, pp. 234-250, 2018.

[43] C. A. Obidoa, B. A. Dodor, V. Tackie-Ofosu, M. A. Obidoa, H. R. Kalisch, and L. J. Nelson, "Perspectives on markers of adulthood among emerging adults in Ghana and Nigeria," Emerging Adulthood, vol. 7, no. 4, pp. 270-278, 2019.

[44] T. Martens, "Impact of the Ghana school feeding programme in 4 districts in Central Region, Ghana," Master's thesis, Wagennigen University, Wageningen, Netherlands, 2007.

[45] H. Kamaludeen, "The impact of the Ghana school feeding programme on enrollment, attendance and retention in $\mathrm{Ga}$ south municipal schools," Master's thesis, University of Ghana, Legon, Ghana, 2014. 